\title{
Primary choledocholithiasis after long-term self-expansible metallic stent for ampullary carcinoma: A rare case
}

\author{
Mohan Joshi, Ashwini Paranjpe, Minakshi Gadhire \\ Department of Surgery, Lokmanya Tilak Municipal Medical College and Hospital, Sion, Mumbai, Maharashtra, India
}

\begin{abstract}
In patients with periampullary carcinoma presenting in the inoperable stage, self-expansible metallic stents (SEMS) are preferred for palliation of jaundice. The primary common bile duct (CBD) stones are very rare in a patient who is treated with SEMS for ampullary cancer. We report here a case of primary CBD stones after 2 years of placement of SEMS, whether, reflux of duodenal contents or foreign body reaction to the stent material is the etiology of the formation of stone is a matter of debate.

Key words Ampullary carcinoma, common bile duct, obstructive jaundice, primary choledocholithiasis, self-expansible metallic stents
\end{abstract}

\section{Introduction}

Endoscopic biliary drainage is currently the standard of care for the palliation of biliary obstruction, in patients with inoperable ampullary carcinoma. Surgical biliary drainage is considered if either endoscopic or percutaneous transhepatic drainage is unsuccessful or not feasible. ${ }^{[1]}$ As compared with palliative surgical techniques, biliary stenting is found to be associated with fewer complications and shorter hospitalization stay with similar survival outcomes. Numerous studies have found metallic stents to be better than plastic stents in patients who are expected to survive more than 6 months. ${ }^{[2]}$ Known complications of stents are stent migration, stent fracture, stent occlusion due to tumor ingrowth or bacterial biofilm formation, cholangitis, cholecystitis, and pancreatitis. ${ }^{[1,3]}$ After a thorough bibliographic search, we believe our case to be the first case of primary choledocholithiasis in a patient

Address for correspondence:

Dr. Ashwini Arun Paranjpe, Gastroenterology surgical services,

Department of Surgery, Lokmanya Tilak Municipal Medical College and

Hospital, Dr. Babasaheb Ambedkar Road, Sion, Mumbai - 400022 ,

Maharashtra, India. E-mail: ashwiniparanjpe14@gmail.com

\section{Access this article online}

Website:

www.jdeonline.in

DOI:

$10.4103 / 0976-5042.165714$ with self-expansible metallic stents (SEMS) for ampullary carcinoma. Endotherapy successfully treated the stones with balloon sweeps.

\section{Case Report}

$\mathrm{U}$ J, a 50-year-old male patient presented with complaints of abdominal pain, yellowish discoloration of eyes, and passing clay colored stools. On clinical examination, the patient was found to be deeply jaundiced. Routine blood investigations revealed conjugated hyperbilirubinemia of $10 \mathrm{mg} / \mathrm{dl}$, high alkaline phosphatase, and raised CA19-9 levels. Abdominal ultrasonography revealed dilated pancreatic duct and common bile duct (CBD) with some nodes in the peripancreatic region. Gall bladder was over distended without gallstones. CBD showed no evidence of stones within. Computerized tomography was done which further confirmed the findings revealing a diffusely infiltrating heterogeneously enhancing lesion at the ampulla of Vater invading the head of the pancreas with the invasion of the portal vein. Side viewing endoscopy was done which showed a mass at the ampulla. The biopsy was obtained, and a temporary plastic stent

This is an open access article distributed under the terms of the Creative Commons Attribution-NonCommercial-ShareAlike 3.0 License, which allows others to remix, tweak, and build upon the work non-commercially, as long as the author is credited and the new creations are licensed under the identical terms.

For reprints contact: reprints@medknow.com

How to cite this article: Joshi M, Paranjpe A, Gadhire M. Primary choledocholithiasis after long-term self-expansible metallic stent for ampullary carcinoma: A rare case. J Dig Endosc 2015;6:123-5. 
was placed in the CBD [Figure 1]. Histopathology revealed well-differentiated adenocarcinoma. As chosen by the patient, soon plastic stent was replaced with uncovered Hanaro Biliary SEMS of MI Tech Korea for long-term palliation of jaundice. After taking some cycles of chemotherapy, patient chose to take homeopathic treatment. However, every 6 months he followed for routine tests and abdominal ultrasound. At the $4^{\text {th }}$ follow-up visit after 2 years patient was asymptomatic, but an abdominal ultrasound revealed multiple $(\geq 3)$ stones in the $\mathrm{CBD}$ within the metallic stent [Figure 2]. Gall bladder showed no evidence of stones. Blood investigations revealed low hemoglobin ( $9 \mathrm{~g} / \mathrm{dl})$ and normal liver chemistry. Endoscopic retrograde cholangiography was done. It revealed metallic stent in situ in CBD with no tumor overgrowth. Cholangiogram revealed multiple stones within the metallic stent [Figure 3]. Stones were extracted with a stone extraction balloon as the use of basket would have been difficult in the presence of SEMS [Figure 4]. CBD was cleared of stones.

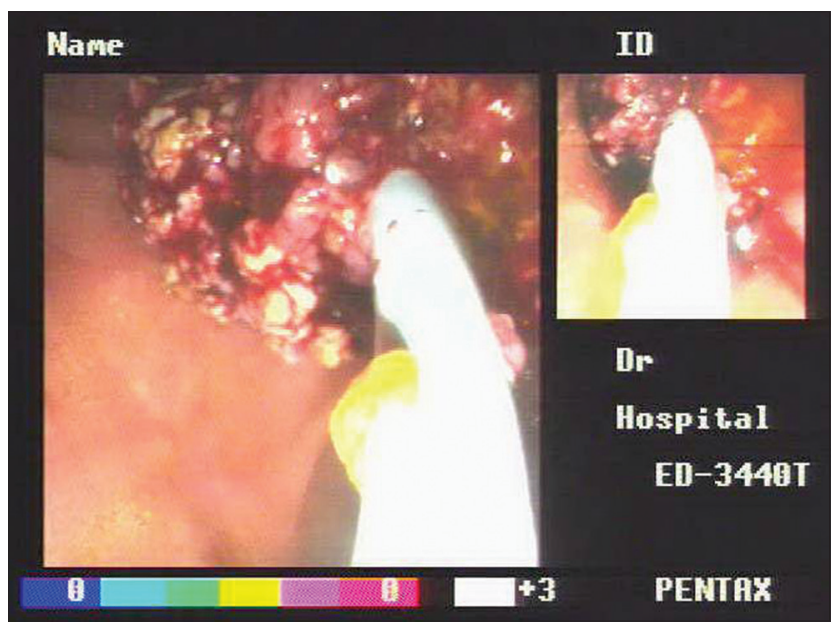

Figure 1: Plastic stent placed in the common bile duct with growth seen at the ampulla of Vater

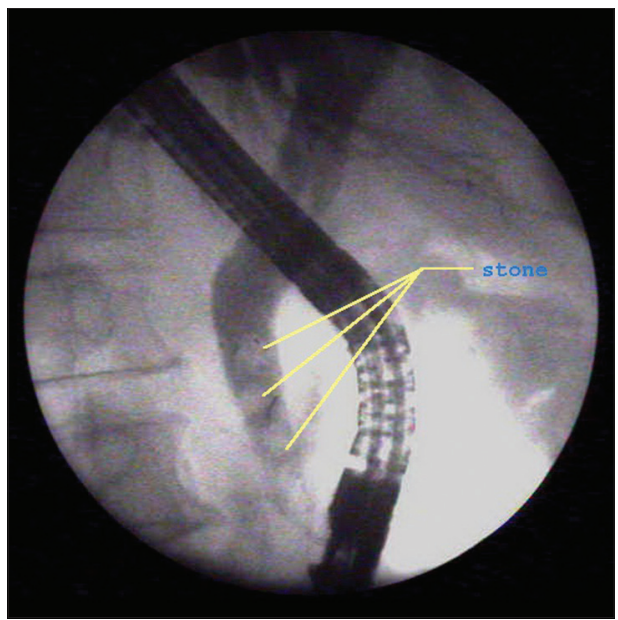

Figure 3: Endoscopic retrograde cholangiography image, cholangiogram revealed multiple common bile duct stones within the metallic stent

\section{Discussion}

Choledocholithiasis is most commonly secondary to stones migrated from the gall bladder. The primary choledocholithiasis (stones formed primarily in the bile duct) is uncommon. Bacterial infection of bile and bile stasis play an important role in the pathogenesis of these stones. ${ }^{[4]}$ Stentoliths are known following long-term plastic stents. ${ }^{[5]}$ However, newly formed primary CBD stones after SEMS for ampullary carcinoma have not been reported before.

Known complications of long-term SEMS in patients with malignant obstructive jaundice are cholangitis, pancreatitis, stent migration, stent occlusion, and stent fracture. Uncovered metallic stents have shown a lower incidence of stent migration as compared to covered metallic stents, but higher chances of tumor ingrowth and stent blockage. ${ }^{[1,6]}$ On detailed review of the literature, primary CBD stone as a complication of long-term SEMS for malignant biliary obstruction is not known to occur.

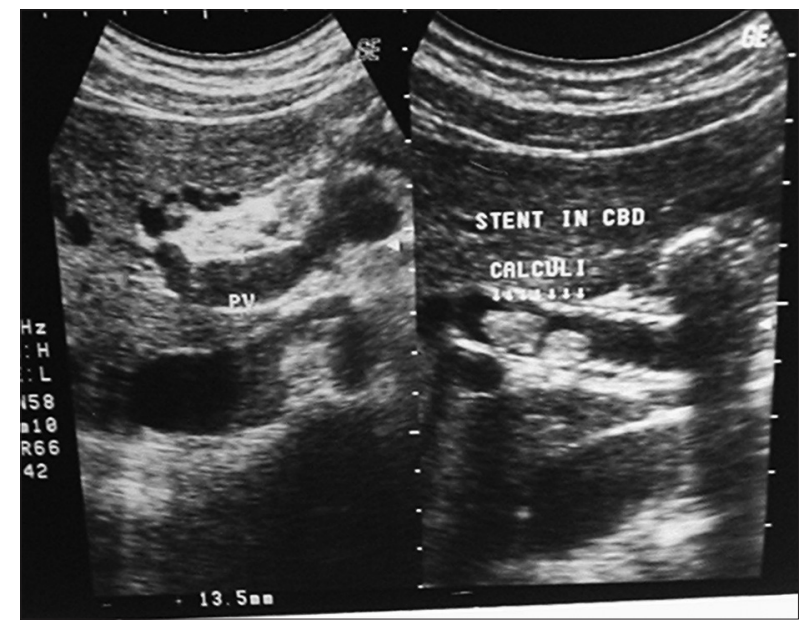

Figure 2: Abdominal ultrasound image showing multiple stones in the common bile duct within the metallic stent

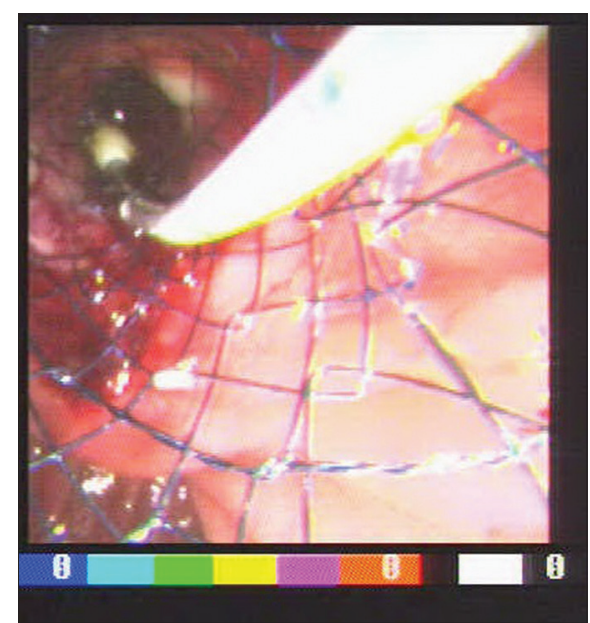

Figure 4: Stones were extracted using the stone extraction balloon in the presence of self-expansible metallic stents 
In this unusual case, proposed theories include reaction to NITINOL or bacterial reflux from the duodenal end of the stent. ${ }^{[7]} \mathrm{CBD}$ stones could become the cause of $\mathrm{CBD}$ obstruction in a patient who has SEMS in CBD. Such stones could be detected by abdominal sonography and could be safely and easily removed by stone extraction balloon. Using baskets for extraction of such stones in the presence of SEMS could be difficult and not recommended.

\section{Financial support and sponsorship}

Nil.

\section{Conflicts of interest}

There are no conflicts of interest.

\section{References}

1. Jaganmohan S, Lee JH. Self-expandable metal stents in malignant biliary obstruction. Expert Rev Gastroenterol Hepatol 2012;6:105-14.

2. Prat F, Chapat O, Ducot B, Ponchon T, Pelletier G, Fritsch J, et al. A randomized trial of endoscopic drainage methods for inoperable malignant strictures of the common bile duct. Gastrointest Endosc 1998;47:1-7.

3. Bakhru M, Ho HC, Gohil V, Wang AY, Ellen K, Sauer BG, et al Fully-covered, self-expandable metal stents (CSEMS) in malignant distal biliary strictures: Mid-term evaluation. J Gastroenterol Hepatol 2011;26:1022-7.

4. Kaufman HS, Magnuson TH, Lillemoe KD, Frasca P, Pitt HA. The role of bacteria in gallbladder and common duct stone formation. Ann Surg 1989;209:584-91.

5. Gupta V, Chandra A, Noushif M, Singh SK. Giant stentolith: Complication of a forgotten biliary stent. Endoscopy 2013;45 Suppl 2 UCTN: E126.

6. Kullman E, Frozanpor F, Söderlund C, Linder S, Sandström P, Lindhoff-Larsson A, et al. Covered versus uncovered self-expandable nitinol stents in the palliative treatment of malignant distal biliary obstruction: Results from a randomized, multicenter study. Gastrointest Endosc 2010;72:915-23.

7. Odabasi M, Arslan C, Akbulut S, Abuoglu HH, Ozkan E, Yildiz MK, et al. Long-term effects of forgotten biliary stents: A case series and literature review. Int J Clin Exp Med 2014;7:2045-52. 